\title{
COLLABORATIVE AND COMPETITIVE STRATEGIES IN VIRTUAL TEAMS OF E- ENTREPRENEURS: A PAN-EUROPEAN PERSPECTIVE
}

\author{
Harry Matlay \\ Birmingham City Business School \\ Birmingham City University, United Kingdom \\ harry.matlay@bcu.ac.uk \\ Lynn M. Martin \\ Manchester Metropolitan University Business School \\ Manchester Metropolitan University, United Kingdom \\ l.martin@mmu.ac.uk
}

\begin{abstract}
Recent advances in Information and Communication Technologies (ICTs) and the advent of the Internet have facilitated the emergence and growth of collaborative strategies amongst small e-Businesses (Matlay \& Westhead, 2005). In addition, during the last decade or so, team-led entrepreneurship has been identified as a highly profitable alternative to single founder entrepreneurship. Recent research suggests that growth oriented, small e-Businesses operating in international e-Markets are more likely to be founded and managed by teams of e-Entrepreneurs (Matlay \& Westhead, 2007). In increasingly globalised and hyper-competitive markets, "virtual teams" of e-Entrepreneurs search, discover and exploit new entrepreneurial opportunities. This type of entrepreneurial team consists of geographically dispersed entrepreneurs who are led by common entrepreneurial interests and interact electronically in order to promote interdependent strategies and fulfil entrepreneurial goals. In this article, an illustrative longitudinal case study of a pan-European virtual team of 24 e-Entrepreneur members is used to evaluate emergent collaborative and competitive strategies in small e-Businesses that are lead and managed by members. Collaborative and competitive strategies of e-Businesses are identified and related outcomes are analysed. Future research opportunities are suggested and pertinent policy recommendations are offered.
\end{abstract}

Keywords e-Business, Collaboration, Competition, Virtual Teams, e-Entrepreneurs, Culinary Tourism, Europe, Small Enterprises 


\section{INTRODUCTION}

Until recently, "traditional" organisational forms, which emerged during the Industrial Revolution, have dominated the economies of both developed and developing nations (Volberda, 1996). In industrially developed countries, traditional organisational forms encompass a wide variety of sizes, locations and economic activities including small and medium-sized enterprises (SMEs). Notably, however, much of the ensuing economic, policy and research interest during the $20^{\text {th }}$ Century focused mainly upon the activities and contribution of large organisations and multinational corporations (Gerschenkron, 1962; Heblich, 2007). As a result, the needs and performance of SMEs were largely neglected (Best, 1990; Hamel \& Prahalad, 1994). The industrial restructuring and large firm downscaling that took place during the 1970s and 1980s generated large scale youth and adult unemployment over a relatively short timescale. The ensuing socio-economic upheaval resulted in a radical shift in national policy and research perspectives as well as the inclusion of smaller firms in their remit (Sabel, 1989; Carlsson, 1994). It is now widely accepted that SMEs make a significant contribution to the economy in terms of employment, productivity and competitiveness and that a healthy and growing small business sector is crucial to the socio-economic and political infrastructure of a nation (Carree \& Thurik, 1998; 1999).

During the 1990s, the dominance of traditional organisational forms has been challenged by the emergence of the Internet and related developments in Information Technology (IT) in general and Information and Communication Technologies (ICTs) in particular. Individually and cumulatively, these developments have facilitated the evolution of new and innovative organisational forms (Matlay and Westhead, 2005). Initially, large organisations adopted e-Commerce as a complementary and efficient strategy to increase their market share (Pinker et al., 2002). For a while, specialist research in this area remained focused on e-Commerce and related activities in large organisations. Following the "Dot-Com meltdown" of 2001, micro- and small e-Businesses have emerged as important players in hypercompetitive and highly profitable e-Markets (Matlay \& Addis, 2003). The drive for sustainable competitive advantage represents an important strategic component of SMEs operating in an increasingly globalised European market (Barnes \& Hunt, 2001). In terms of internationalisation strategies, those e-Businesses that have achieved successful expansion beyond their domestic markets are increasingly dependent on collaborative strategies that offer significant competitive synergies beyond their organisations' scope and scale (Matlay \& Westhead, 2007).

There exists a growing body of specialist knowledge devoted to various aspects of small eBusinesses and their activities. Nevertheless, much of the current research and theory formation in this field remains dedicated to traditional organisational forms, including their contribution and sustainability (Matlay, 2008). Much of the existing research provides a snapshot of the motivation, behaviour and strategies of traditional entrepreneurs and/or the formation, development and operation of conventional businesses. It does not incorporate an analysis of the motivation, behaviour and strategies of e-Entrepreneurs and/or related e-Business formation, development and operation. Furthermore, most traditional small businesses are commenced and managed by a sole entrepreneur and incorporate rare or isolated instances of collaboration with other stakeholders. Consequently, the vast majority of traditional small businesses are limited by the vision and skills of the founding entrepreneur and fail to develop or grow beyond their initial size or localised niche market (Matlay \& Westhead, 2005). In contrast however, most e-Entrepreneurs tend to team up with similarly oriented individuals, either prior or soon after commencing their e-Businesses, as well as collaborate with customers, suppliers and competitors. Importantly, e-Entrepreneurs are prepared to adopt e-Collaborative strategies in order to pursue their growth oriented and internationalisation goals (Matlay \& Westhead, 2007). There is a marked paucity of research focusing on e- 
Entrepreneurs in general and virtual teams of e-Entrepreneurs in particular. In this article we focus specifically upon the collaborative and competitive strategies of e-Entrepreneurs and their small eBusinesses who formed a pan-European virtual team.

The structure of the article is as follows. First we define the nature of e-Business in terms of the types of small e-Businesses developing in Europe. This then leads onto a review of European contexts in e-Business and to e-Collaboration (in the form of virtual teams of e-Entrepreneurs) as a competitive strategy. Although internationalisation is naturally part of this process, the wider literature on internationalisation in small firms is not considered here because the focus of this paper is on virtual team formation, development and operation across time and space and the strategies embedded in this process, not the internationalisation strategies of these firms. We then justify our research approach which involved an illustrative longitudinal case study of a pan-European virtual team of 24 e-Entrepreneurs operating in the tourism industry. This then leads to an analysis of the findings in which we identify the collaborative and competitive strategies of a team of eEntrepreneurs and analyse the related outcomes of these strategies. The paper then concludes with a brief summary of the future research opportunities arising from this work and with pertinent policy recommendations.

\section{LITERATURE REVIEW}

\section{E-Business: Definitions, Conceptual and Contextual Considerations}

In this section we define and categorise e-Businesses as well as introduce their competitive and collaborative strategies. In recent years, e-Business has emerged as a strategic way to improve communication (via Intranets) within organisations as well as enhance collaboration (via Extranets) with key external stakeholders, such as customers, suppliers and government representatives (Byrd, 2001; Basu \& Kumar, 2002; Meroño-Cerdan et al., 2006). Importantly, however, the adoption of eBusiness was perceived as a way to achieve sustainable competitive advantage in an increasingly globalised economy (Martin \& Matlay, 2001; 2003; Li et al., 2004). There is considerable confusion of terms relating to doing business over the Internet (Melao, 2009). This is symptomatic of media coverage as well as academic and practitioner publications. For example, some authors use terms such as "e-Business", "e-Commerce" and "Internet Trading" interchangeably while others tend to differentiate between specific aspects relating to each of these terms (Papazoglou \& Ribbers, 2006; Laudon \& Traver, 2008).

Zwass (1996, p. 3) pioneered a comprehensive e-Business definition, which incorporated “... the sharing of business information, maintaining business relationships and conducting business transaction by means of telecommunication networks". Although this definition underlies much of the early research in e-Business, it has not become standardised or been universally accepted. Bandyo (2002) points out that the concept of e-Business and e-Commerce were first mentioned in academic literature during the late 1980s in order to differentiate between traditional, paper based transactions and electronically conducted exchanges. In this context, Lucas (1996) argues that even the most basic e-Business models must rely exclusively on electronic transactions as opposed to traditional paper based exchanges. Timmers (2000) posits that a "true" e-Business should encompass the whole array of electronic trading steps, such as online marketing, ordering and remittance facilities as well as complaints, returns and after sales support. For the purpose of this research study we adopted Stephen Chen's (2001:2) wider definition of e-Business which includes buying and selling on the Internet, as well as supporting/servicing customers and collaborating with various business partners via the Internet. Matlay's (2004) overview of e-Business models suggests 
that there are five basic types of electronic transactions in which e-Businesses can buy, sell and interact with customers or business partners online:

1. Business-to-Business (B2B) - which involves the marketing and sales of products/services between businesses.

2. Business-to-Customer (B2C) - where businesses target products/services directly and exclusively at private customers.

3. Business-to-Government (B2G) - entails businesses delivering electronically a range of products/services to Government or government sponsored institutions.

4. Business-to-Portal (B2P) - involves the marketing of products/services on an Internetbased portal.

5. Business-to-Affiliate (B2A) - includes the marketing of an affiliate's products/services on a commercial website.

The research reported in this paper focused on small e-Businesses which satisfied Chen's (2001) definition and employed one or more of the types of electronic transactions listed above. However, it should be noted that there are also hybrid organisational forms which carry out only some aspects of their transactions over telecommunication networks (see Martin \& Matlay, 2003; Matlay \& Addis, 2003). As such they do not conform either to the traditional paper-based organisational form nor exclusively to electronic transaction,and the supportive and collaborative nature of "true" eBusinesses. Nevertheless, hybrids seem to operate successfully in almost every sector of the economy in both industrially developed and developing nations (Matlay, 2004). For the purposes of this article, hybrid organisational forms were specifically excluded from the study. Given the importance of e-Business in the competitiveness and strategies of businesses, including SMEs, the next section examines the role of e-Business to the economic survival of Europe and the need for pan-European virtual collaboration between SMEs.

\section{E-Business: A European Perspective}

Tilly et al., (2007), in their seminal book published to coincide with the 50th anniversary of the European Union (EU), provide a comprehensive overview of contemporary European socioeconomic and political development since the end of the Second World War in 1945. They chart both the enlargement of EU membership from 6 founding members in 1957 to 27 in 2007 and the economic challenges faced by European countries in relation to competition, innovation, globalisation and structural changes within the continent itself as well as vis-à-vis other industrially developed and developing nations.

In terms of future economic development of the EU, the authors highlight that “... the Lisbon agenda of the EU which aims at making the EU the most competitive economy by 2010 has emphasised the goals of higher employment and higher growth in the Community, by placing emphasis on the role of information and communication technology [ICT] in a knowledge society" (Tilly et al., 2007, p. 3). This highlights the important role that ICT investment, innovation and eBusiness adoption will play in European structural adjustment at both macro- and micro-economic levels.

It is widely acknowledged, however, that ICT, innovation and e-Business adoption patterns vary considerably across EU countries (Welfens, 2007). Furthermore, ICT usage, innovation investment and e-Business adoption rates in Europe have not contributed to productivity improvements and economic growth at the high levels experienced in the US and elsewhere (McGuckin \& Van Ark, 2005; Pols, 2007). Various solutions have been suggested to narrow the growing productivity gap 
between European countries and their international competitors (Van Ark, 2006; Inklaar et al., 2005). At a macro-economic level, there is a need for European countries to implement complementary structural policies, including labour market and educational reforms (Beugelsdijk \& Eijffinger, 2003; Sapir, 2006; Artis \& Nixon, 2007). At a micro-economic level, most observers recommend an increase in ICT investment and the acceleration of e-Business adoption, in particular within the SME sector, which accounts for just over 99\% of all economically active units in Europe (Peet et al., 2002; Davis, 2003; Erumban \& De Jong, 2006).

The drive for sustainable competitive advantage represents an important strategic component of SMEs operating in a largely globalised European market (Matlay \& Westhead, 2005). In terms of internationalisation strategies, those SMEs that have achieved successful growth beyond their domestic markets have become increasingly dependent on a variety of collaborative strategies and approaches. Some collaborative partnerships, including "virtual teams" of e-Entrepreneurs, offer significant competitive synergies that exceed their individual organisational scope and scale, as well as technical, financial and human resource support (Matlay \& Westhead, 2007). Importantly, however, recent research on value creation in e-Business adoption has positioned European firms at a disadvantage as compared with those operating in the US (Amit \& Zott, 2001; Schubert \& Leimstoll, 2008). Similarly, the productivity gap between European e-Businesses and their counterparts in the US continues to widen despite growing investment in, and support for, ICT innovation in EU member countries (Peet et al., 2002; Pols, 2007). Innovative organisational forms and related collaborative links amongst European businesses could offer a solution to both these problems and contribute significantly to national and regional development (Hamdouch, 2008).

The next section examines the role of electronic collaborative links between small growth-oriented e-Businesses. In particular it justifies the conceptual and practical potential of "virtual teams" to help e-Entrepreneurs of such businesses identify and develop collaborative and competitive strategies. For the purposes of this paper, we define e-Entrepreneurs as individuals who seek and validate entrepreneurial opportunities on the Internet and convert them into marketable goods and services which are promoted and/or sold exclusively online. Typically, they are growth oriented individuals who use competitive and collaborative strategies to further their entrepreneurial goals. Their growth orientation as well as their proactive, competitive and collaborative approaches differentiates them from "lifestyle" small e-Business owner/managers who mostly rely upon reactive survival strategies.

\section{E-Collaboration as a Competitive Strategy}

According to Waesche (2003), the uneven development of e-Entrepreneurship in some parts of Europe has been attributed to the absence of regional "entrepreneurial ecosystems" that facilitate cooperation amongst entrepreneurs, venture capitalists, legal experts and other specialist support providers. In contrast, US enterprises appear to have benefited significantly from entrepreneurial ecosystems, such as those operating in the Silicon Valley region. In addition, collaborative links with academic, research and financial networks has ensured rapid response and focused support for innovation opportunities that have been identified and converted by enterprises operating within loosely defined entrepreneurial ecosystems (Kenney, 2003).

Typically, entrepreneurial teams provide support to, and benefit from, collaborative networks of geographically dispersed SMEs that share common goals (Matlay \& Westhead, 2005). In this context, Hamdouch et al. (2008, p. 3) argue that “... innovation, notably technological (but also organisational and commercial) is now recognised as a collective process, and not just as a physical and social phenomenon stemming from the genius of an inquiring and ingenious mind". In his review of successful innovation in European SMEs, Cobbenhagen (2000, p. 34) compares and contrasts the needs and contribution of small and large firms and concludes that "... most of the 
growth in employment and added value can be attributed to SMEs ... and innovation is as important to them as to large firms". Successful innovation that takes place in resource challenged SMEs can be facilitated and supported by a collective process of collaboration and learning that offsets the size-related scope and scale advantages of larger firms (see Matlay, 1998; Cumbers et al., 2003). The innovative capacity of SMEs to adapt and react to rapidly changing market conditions is recognised as their most important competitive advantage (Schubert \& Leimstoll, 2008).

There has been a growing body of research concerning SMEs and their networking, with much of this work focusing on the structural nature of these networks, the relationships between SMEs which network and the benefits they can gain from collaboration (e.g., O'Donnell, 2004; Street \& Cameron, 2007; Welter \& Kautonen, 2005). However, Street and Cameron's (2007) literature review of more than 200 articles on small businesses and their external relationships (including networks) found there was limited research on the strategies of SMEs which have formed such partnerships. In addition, little of this research has examined the nature of SME networking via the Internet. This paper fills the gap in knowledge by examining the collaborative and competitive strategies of e-Entrepreneurs who have formed a virtual or online strategic business network.

O'Donnell (2004) argues that the existing research on and findings concerning SMEs and their networking has been largely inconclusive. O'Donnell attributes this to the lack of conceptual differentiation of networks on three dimensions: level of networking (limited, medium and extensive), degree of networking proactivity (reactive, medium, proactive), and the strength of networking ties (weak, medium and strong). In the paper we address this problem by focusing on a specific type of business network using these dimensions: the emergent organisational form "virtual teams" of e-Entrepreneurs. These virtual teams consist of geographically distributed entrepreneurs who interact through interdependent tasks and are led by common entrepreneurial interests and goals (Matlay, 2003a). The majority, if not all, of their interactions take place outside traditional face-to-face meetings, and are conducted via email, instant messaging, video and mobile conferencing as well as other Internet-based interactive technologies (Matlay, 2003b). Conceptually speaking, such virtual teams are a subset of SME business networks because the e-Entrepreneurs have medium to extensive levels of networking, have a high degree of networking proactivity (that is, they proactively seek strategic goals), and have medium to strong networking ties due to the close working relationship which develops between team members. More significantly from a European perspective, virtual teams of e-Entrepreneurs illustrate the adaptive capacities of small eBusinesses to respond to the opportunities and challenges associated with the rapidly expanding global $e$-Economy (Matlay \& Westhead, 2007).

Typically, existing "virtual team" research focuses upon either virtual teams of employees in general or entrepreneurial teams within SMEs in particular (Matlay \& Westhead, 2005). Previously, we researched the emergence of virtual teams of e-Entrepreneurs in Europe and evaluated their contrasting competitive strategies. The findings provided high level insights related to competitive strategies across various virtual teams of e-Entrepreneurs. In this article we focus upon an illustrative case study of collaboration between e-Entrepreneurs that are members of a single virtual team. The results of our longitudinal case study research offer an in-depth analysis of collaborative strategies within a virtual team of e-Entrepreneurs in order to provide a better understanding of related outcomes.

In summary, despite the growing importance of e-Businesses in Europe and the recent policy focus on e-Entrepreneurship, many of the conceptual and contextual aspects of virtual teams of eEntrepreneurs are yet to be comprehensively researched. In this article we focus upon an illustrative longitudinal case study of a virtual team of 24 e-Entrepreneurs in the European tourism sector who run small growth oriented e-Businesses, in which they develop collaborative and competitive 
strategies, in order to better understand the advantages accruing to owner/managers and their employees.

\section{RESEARCH APPROACH}

\section{Sector, research method and rationale}

Tourism remains one of the fastest growing sectors in both developed and developing economies and is expected to continue to expand despite the unfavourable economic conditions affecting countries in the European region as well as other popular destinations across the world (WTO, 2007). Over the last two decades, research has struggled to keep up with ongoing developments in the rapidly evolving tourism sector of the European economy. Furthermore, such research that exists often suffers from a number of inherent shortcomings, such as the lack of generalisation across time and space, which renders a large proportion of emergent results problematic (Matlay, 2003a).

Some authors aim to address the issue of generalisation by using a pragmatic mix of quantitative and qualitative approaches (Pansiri, 2005; 2006). This triangulation of methods has met with some success in ensuring partial generalisation of tourism research results because the advantages of one approach counteract the disadvantages of another (Decrop, 1999). However, the mix or singular use of quantitative and qualitative methods is not deemed sufficient to ensure empirically rigorous results that hold across a wide variety of relevant contexts (Walle, 1997). For example, there is a tendency in tourism studies to conduct localised research results (e.g., in a single country), perhaps because of the challenges of employing quantitative and/or qualitative methods, which has resulted in a lack of cross-border results which would result in better generalisation (see Matlay, 2005). In addition, the rapidly evolving nature of the tourism sector, as well as that of SME business networks and virtual teams, implies that such phenomena should be studied over time rather than as one-time "snap shots" (O'Donnell, 2004).

As the purpose of this study was to conduct research which had a greater level of generalisability across time and space we chose a longitudinal cross-border case study of e-Entrepreneurs who operated within a virtual team. According to Beeton (2005), case studies have been used extensively in tourism research and this method has been applied consistently across a wide range of relevant contexts. There is, however, a marked paucity of longitudinal studies in tourism related topics (Ritchie, 2005). The choice was influenced by our determination to use an "integrative" research method that goes beyond presenting data on case examples.

The longitudinal dimension of this research study adds conceptual and contextual consistency, and greater empirical rigour, to the qualitative depth of analysis than would have been possible if we had conducted a one-time case study which only provided a "snap shot" of the dynamics of the virtual team. For example, over time we developed richer insights into the various influences that have impacted upon European tourism e-Businesses and the changes that affected their competitive strategies. The study also covers a relatively long (1992 to 2008) time span and therefore facilitated a more critical and empirical rigorous overview of the impact that collaboration has on competitive strategy within the dynamics of virtual team management.

\section{Data collection and analysis}

This paper provides an overview and analysis of the emergent results of an illustrative case study of a virtual team. In total 24 core members of a virtual team, who were e-Entrepreneurs each running a small e-Business, were selected from a larger research population of firms operating in the 
European culinary tourism sub sector (GIR, 2008). The "Culinary Tourism Virtual Team" (CTVT) was specifically selected from a wider sample of 15 European virtual teams that form part of a larger longitudinal, multiple case study research. In terms of membership size, sectoral spread, collaborative tendencies and competitive strategies, it is indicative of the type of virtual team of eEntrepreneurs that operate in the European tourism industry.

Each of the 24 e-Businesses in CTVT is lead by an e-Entrepreneur and s/he was interviewed every six months over the 1992 to 2008 period. Quantifiable data collected during these interviews was codified using a simplex coding technique in order to produce research data that is comparable across the whole of the virtual team for the duration of the longitudinal study. Non quantifiable data and verbatim quotations were analysed manually and stored on high density electronic media. As reliable software for the analysis of qualitative data was not available until about 2001, a decision was made to continue with the manual analysis of emergent qualitative data.

The virtual team investigated in this research study provides a rich and valuable context for a case study analysis of the collaborative and competitive strategies of 24 core e-Entrepreneurs and their eBusinesses. Core e-Entrepreneurs represent a crucial characteristic of this type of virtual team, both in terms of membership stability and strategy formulation and/or implementation. We chose to exclude peripheral members from this research study as they do not impact significantly upon the decision making processes of the virtual team under investigation.

As an emergent organisational form, this case is illustrative of many virtual teams that operate successfully in the European culinary tourism industry. The results were mapped and key emergent aspects are discussed here under three headings:

1. Virtual Team Formation, Membership and Development

2. Virtual Team Collaborative and Competitive Strategies

3. Virtual Team and e-Marketing Platforms

\section{RESEARCH FINDINGS}

\section{Virtual Team Formation, Membership and Development}

The origins of the Culinary Tourism Virtual Team (CTVT) can be traced to an exploratory meeting that involved five entrepreneurs and took place in March 1992 during a trade exhibition in Paris. The five entrepreneurs, who were fluent in English, owned and operated tourism businesses located in the UK, France, Austria, Hungary and Poland. During the previous two years, these entrepreneurs had exchanged telephone calls and emails that related to queries and requests raised by some of their regular customers. Over time, it became obvious that a growing number of requests for specific destinations were interrelated and followed a well defined pattern, involving cross-national and international destinations. Invariably, requests for multiple international destinations referred to historical, cultural and culinary aspects of specific European countries.

As demand for overseas destinations increased rapidly, the five entrepreneurs continued cooperating with each other on a "good will" basis, which proved mutually beneficial in terms of turnover and profit margins. In the autumn of 1991, the French entrepreneur suggested a meeting to coincide with a prestigious tourism exhibition and offered to facilitate the trip as well as provide accommodation and transport to and from the venue. Following intense discussions and negotiations, it was agreed at the Paris meeting to formalise a "virtual team arrangement" between the five entrepreneurs. The virtual team aimed to focus exclusively on cooperation related to business referrals and knowledge 
exchanges in the rapidly expanding European culinary tourism. Preliminary strategies for the growth of their virtual team and related businesses were also proposed at this meeting and various suggestions discussed in detail.

Between 1993-2003, CTVT grew and developed considerably to incorporate a core membership of 24 e-Entrepreneurs, representing most European countries. Since 2000, CTVT has been operating as a highly profitable virtual team with a stable membership and a reputation for high quality culinary tourism destination and related services. Interestingly, from conception, the use of ICTs and, at a later stage, the adoption of electronic business (e-Business) and mobile business (m-Business) became an important and profitable inter-team business strategy. Although the French eEntrepreneur acts as an informal "lead entrepreneur", all important strategic decisions in CTVT are made in common and subject to a majority agreement of at least two-thirds of core entrepreneurs.

Core membership comprises those e-Entrepreneurs who both consider themselves, and are acknowledged by other team members, to be significantly and permanently involved in the commercial activities of this virtual team. They derive all or a major part of their turnover from the cooperative activities of CTVT. In addition to the core membership, there are between 10 and 15 eEntrepreneurs that represent the peripheral membership of the virtual team. These peripheral members are only involved on a temporary or ad hoc basis and derive a relatively small proportion of their turnover from activities that are directly attributable to CTVT. Importantly, peripheral members are not called upon to vote or make a strategic contribution to any aspect of virtual team management or development. Nevertheless, they make a contribution to the delivery of "overspill" and "unforeseen" destinations and related services.

\section{Virtual Team Strategic Convergence and Competitive Strategies}

Most virtual team formation can be attributed to actual or perceived competitive advantages relating to collaborative niche market strategies. Previous research by Matlay \& Westhead (2005; 2007) established that there is no prescribed or standard approach to cooperative or competitive strategies in virtual teams of e-Entrepreneurs. Preliminary results emerging from the longitudinal in-depth investigation of the 24 e-Entrepreneurs and their e-Businesses comprising the core membership of the CTVT have highlighted a consistent and distinct convergence in their respective competitive strategies. The main aspects of strategic convergence amongst e-Business in CTVT can be usefully summarised as follows:

a. Rapid adoption of ICTs and related e-Business processes, leading to early scope and scale advantages in targeted niche e-Markets

b. Customisation, across the virtual team core membership, of standardised accounting, financial, marketing and after sale functions, leading to considerable cost reduction and effective resource utilisation.

c. Mutual support in important operational aspects, which include technical, financial and human resource management, leading to considerable reduction of operative costs and increase in per capita profits.

d. Adoption and the development of common marketing platforms and strategies, leading to significant growths in annual turnover rates.

e. Development of pricing review mechanisms that have resulted in standardisation and stabilisation benefits across the virtual team.

f. Niche market expansion and consolidation at domestic levels, which have facilitated overall internationalisation efforts in all e-Businesses within the team. 
g. Adoption of an inter-team transparency and support policy based upon mutual trust and "win-win" conflict resolution.

In both absolute and relative terms, the collaborative strategies adopted by the 24 e-Businesses in the CTVT resulted in considerable and measurable competitive benefits. The focus on measurable benefits that could be compared across the team emerged during the formative first three years of CTVT and became an important strategic goal for each e-Entrepreneur. The intensity of their collaborative strategies is symptomatic of both individual e-Business and virtual team competitive strategies. In absolute terms, three factors - overall cost reduction, effective resource utilisation and increase in turnover - delivered significantly higher profit rates as well as above average entrepreneurial returns. In addition, operational support and niche market expansion provided business stability and enhanced these e-Entrepreneurs' confidence in their collaborative strategies.

In relative terms, mutually supporting collaborative activities within the CTVT resulted in significant human resource gains at e-Business level as well as enhanced managerial, technical and marketing skills for the e-Entrepreneur. In an economic environment dominated by micro- and small tourism businesses, which are on average four times less likely than larger organisations to engage in collaborative activities (see Lockett \& Brown, 2006), the virtual team setting provided significant short and long-tem competitive benefits. Furthermore, it appears that each e-Business achieved and maintained sustainable competitive advantage by collaborating with members of the virtual team while competing successfully against firms of all sizes within the same niche market. Their ability to compete successfully might be attributable to the decision of the CTVT's core members that only one e-Entrepreneur from each country was permitted to join.

\section{Virtual Team and e-Marketing Platforms}

Traditional European small firms are usually associated with either manual, or at best, semiautomated business and transaction processes that are comparatively slow and inefficient. Most eBusiness platforms follow "evolutionary" development patterns that often lag behind the "state of the art" ICTs employed by their fast-growth competitors that operated in rapidly evolving global eMarkets. The longitudinal analysis of CTVT confirmed that manual and semi-automated business processes only prevailed for a short period amongst the five founding e-Businesses. By the end of 1995, these businesses were fully automated and intensely geared towards evolving ICTs that went beyond email exchanges between founding e-Entrepreneurs and amongst their employees. Nevertheless, these businesses continued to rely upon "word-of-mouth" and paper-based marketing strategies that only partially addressed their collaborative efforts. One year later, successful full adoption of e-Business platforms, including Electronic Data Interchange (EDI) technologies, enabled these e-Entrepreneurs to pursue "revolutionary" development patterns that significantly enhanced collaboration within the virtual team, facilitated membership expansion and the development of a common platform for the internationalisation of culinary destinations and related services.

All the important items on the original agenda when the CTVT formed were successfully completed by 1997 and core members proceeded to consolidate their achievements. Over the next ten year (1998 - 2007) period, core members worked collaboratively to integrate and perfect their businessto-business (B2B) transactions into a common supply chain management system. In addition, they decided to consolidate their domestic and international Business-to-Customer (B2C) transactions into a common e-Marketing system. Both of these strategies met with considerable success. Unfortunately, however, efforts to integrate these collaborative operative systems within relevant administrative and after sale functions were met with technical, cultural and language barriers as well as considerable staff resistance to radical change, common to many small firms (Martin, 2005). After experimenting with various models and electronic platforms, the core e-Entrepreneurs decided 
to abandon this strategy and continue to rely on firm specific administrative and after sale support systems.

The failure to achieve total integration of their e-Business, administrative and after-sales systems underlines both the advantages and limitations attributable to collaborative models of competitive strategy, including virtual teams (Frohlich, 2007). Most collaborative models of entrepreneurial activity share a degree of scope, scale and cost advantage, including clusters, networks and joint ventures. Higher collaborative intensity and levels of trust as encountered in virtual teams can therefore be expected to offer greater than average scope, scale and cost advantages. In addition, these can also provide better risk management and flexibility of delivery (Ball \& Queyranne, 2006). This is particularly relevant to CTVT, where high intensity collaborative and integrative strategies have resulted in greater than average entrepreneurial return as well as higher levels of business trust and interaction amongst the core membership.

There are however, other determinant factors that impact upon collaborative entrepreneurial models and limit outcomes in general and cost advantages in particular (Wu \& Kleindorfer, 2005). The direct cost advantage accruable is mostly determined by the level of operational planning, staffing, maintenance and after sale support. In the case of CTVT, expected direct and indirect cost advantages related to high levels of strategic planning, collaboration and integration were reduced by factors that were largely beyond the e-Entrepreneurs' control. A deliberate strategy to maintain only one core representative in each European country, however, had a de facto limiting effect upon the domestic scale advantage, but contributed an equivalent or greater increase in the international exposure of relevant destinations. On balance, however, the advantages accruable to core CTVT members were perceived to significantly exceed the potential of "solo" entrepreneurs operating in the same niche market.

\section{DISCUSSION}

Previous research has highlighted a marked paucity of empirically rigorous studies that focused upon SME business networks in general and virtual teams of e-Entrepreneurs in particular. Similarly, considerable knowledge gaps exist in relation to the nature of small business networking and the intensity of collaborative activities amongst entrepreneurs. Furthermore, a growing body of specialist research suggests that growth oriented, small e-Businesses that operate in international eMarket niches are more likely to be founded and managed by teams of e-Entrepreneurs. Not much is known, however, about the nature and intensity of collaboration amongst e-Entrepreneurs within virtual teams. In this article we focused specifically upon the collaborative strategies adopted by eEntrepreneurs who are members of a virtual team operating in the European tourism industry. The emergent results have clarified a number of important aspects appertaining to the membership of virtual teams of e-Entrepreneurs as well as related collaborative and competitive strategies.

The European tourism industry comprises a large and heterogeneous population of traditional, hybrid and e-Businesses of various sizes, locations and economic activities. It is important that we distinguish conceptually as well as empirically between different types of SMEs and their collaborative activities. The strength of ties, proactivity and high level of collaboration amongst eEntrepreneurs in the CTVT was evident throughout the period of research. Arguably, their collaborative strategies can explain, at least in part, the long-term success of this virtual team of eEntrepreneurs. In comparison, other SME business networks within the same industry have underperformed or even failed to survive. 
In addition to the conceptual and empirical results emerging for this research study, there are a number of policy recommendations that we would like to offer. In the light of the growing number of e-Businesses operating in the tourism industry, we recommend that policy makers at national and European levels divert a proportion of designated research funding from "traditional" entrepreneurship research to emergent organisational forms such virtual teams of e-Entrepreneurs. This would facilitate a better understanding of e-Business formation and the development of eEurope across a broader organisational spectrum. By providing wider and better pan-European perspectives, more research in this area would complement the US models that are often used to define new forms of business and this might also be true for Australasia and other regions where virtual teams are emerging as a way to promote online entrepreneurship.

As with other qualitative research studies, we acknowledge a number limitations relating to sample size and representativeness. Caution is recommended in the interpretation of findings and conclusions as well as the generalisation of emergent results. Nevertheless, our longitudinal and empirically rigorous approach presents distinct advantages in terms of findings relating to virtual teams of e-Entrepreneurs across a relatively long time span and cross border collaborative activities.

\section{CONCLUSION AND FUTURE RESEARCH AGENDA}

The results emerging from the longitudinal study and meta-analysis of the Culinary Tourism Virtual Team (CTVT) case provide empirically rigorous insights into the way in which strategy underpins virtual team formation, development and operation across time and space. The CTVT was initially formed to promote and support cooperation between growth oriented e-Entrepreneurs operating in the rapidly expanding European culinary tourism sector. Since its inception in 1992, this virtual team has grown to incorporate 24 core e-Entrepreneurs and 15 peripheral members. In terms of eMarket growth and penetration, it is currently represented in most European countries. Collaborative strategies adopted by these e-Entrepreneurs have resulted in the rapid adoption of ICTs and e-Business processes, the standardisation of accounting, financial, marketing and after sale functions, continuous support in technical, financial and human resource management and the development of competitive e-Marketing platforms and strategies.

Members of CTVT have achieved early successes in niche market expansion and consolidation in domestic markets as well as overall internationalisation of their e-Businesses within the highly competitive European culinary tourism sector. Consistently higher per capita turnover and profit levels have been recorded in each of the e-Businesses in this virtual team. Bigger profits are mostly the result of significant scope, scale and cost advantages that can be directly attributed to team wide collaborative strategies. Importantly, CTVT members claimed that considerable advantages accrued to virtual team membership.

More research is needed into the formation, development and business strategies adopted by eEntrepreneurs who belong to virtual teams. For example, very little is known about financial and managerial issues, harvesting and exit strategies, family involvement and succession planning in the context of virtual teams. There is a marked paucity of empirical studies on employment, reward, training and human resource development strategies adopted in virtual teams of e-Entrepreneurs. Future research of this kind regarding virtual teams of e-Entrepreneurs is critical because it will help ensure that studies in this area are incorporated into "mainstream" entrepreneurship research. 


\section{REFERENCES}

Amit, R. \& Zott, C. (2001) "Value Creation in e-Business", Strategic Management Journal, Vol 22 No 6/7, pp. 493-520.

Artis, M. \& Nixon, F. (Eds.) (2007) The Economics of the European Union: Policy and Analysis, 4th edition, Oxford University Press, Oxford.

Ball, M. \& Queyranne, M. (2006) Toward robust revenue management: Competitive analysis of online booking, Research Paper No. RHS 06-021, University of Maryland.

Bandyo, N. (2002) E-Commerce: Context, Concepts and Consequences, McGraw-Hill, Maidenhead.

Barnes, S. \& Hunt, B. (2001) E-Commerce and V-Business: Business Models for Global Success, Butterworth-Heinemann, Oxford.

Basu, A. \& Kumar, A. (2002) "Research Commentary: Workflow Management Issues in eBusiness", Information Systems Research, Vol 13 No 1, pp. 1-14.

Beeton, S. (2005) "The Case Study in Tourism Research: A Multi-Method case Study Approach", in: B.W. Ritchie, P. Burns and C. Palmer, C. (eds.) Tourism Research Methods - Integrating Theory with Practice, CABI Publishing, Wallingford, pp. 37-48.

Best, M. (1990) The New Competition: Institutions of Industrial Restructuring, Harvard University Press, Boston, MA.

Beugelsdijk, M. \& Eijffinger, S. (2003) The Effectiveness of Structural Policy in the European Union: An Empirical Analysis for the EU-15 during the Period 1995-2001, CEPR Discussion Paper No. 3879, Centre for Economic Policy Research, London.

Byrd, T. (2001) "Information technology: core competencies, and sustained competitive advantage", Information Resources Management Journal, Vol 14 No 2, pp. 27-36.

Carlsson, B. (1994) "The Rise of Small Business: Causes and Consequences", in: W.J. Adams (ed.) Singular Europe: Economy and Polity of the European Community After 1992, University of Michigan Press, Ann Arbor, MI.

Carree, M. \& Thurik, A.R. (1998) "Small Firms and Economic Growth in Europe", Atlantic Economic Journal, Vol 26 No 1, pp.137-146.

Carree, M. \& Thurik, A.R. (1999) "Industrial Structure and Economic Growth", in: D.B. Audretsch \& A.R. Thurik (eds.) Innovation, Industry Evolution, and Employment, Cambridge University Press, Cambridge.

Chen, S. (2001) Strategic Management of e-Business, John Wiley \& Sons, Chichester.

Cobbenhagen, J. (2000) Successful Innovation: Towards a New Theory for the Management of Small and Medium-sized Enterprises, Edward Elgar, Cheltenham.

Cumbers, A., Mackinnon, D. \& Chapman, K. (2003) "Innovation, collaboration, and learning in regional clusters: a study of SMEs in the Aberdeen oil complex", Environment and Planning A, Vol 35 No 9, pp. 1689-1706.

Davis, P. (2003) "Widening Participation and the European Union: direct action - indirect policy?", European Journal of Education, Vol 38 No 1, pp. 99-116. 
Decrop, A. (1999) "Triangulation in Qualitative Tourism Research", Tourism Management, Vol 20 No 1, pp. 157-161.

Erumban, A.A. \& De Jong, S.B. (2006) "Cross-country differences in ICT adoption: A consequence of Culture?", Journal of World Business, Vol 41 No 4, pp. 302-314.

Frohlich, M.T. (2007) "e-Integration in the Supply Chain: Barriers and Performance", Decision Sciences, Vol 33 No 4, pp. 537-556.

Gerschenkron, A. (1962) Economic Backwardness in Historical Perspective, Harvard University Press, Cambridge.

GIR (2008) Virtual Teams of e-Entrepreneurs in Europe: A Longitudinal Perspective, Global Independent Research, Coventry.

Hamdouch, A. (2008) "Conceptualising Innovation Clusters and Networks", The Spirit of Innovation Forum, 14-16 May, Tacoma-Seattle, Washington, USA.

Hamdouch, A., Laperche, B. \& Munier, F. (2008) "The collective innovation process and the need for dynamic coordination: general presentation", Journal of Innovation Economics, Vol 2 No 2, pp. 3-13.

Hamel, G. \& Prahalad, C.K. (1994) Competing for the Future, Harvard University Press, Boston.

Heblich, S. (2007) Self-Reliant Individuals and Pro-Active Companies, Discussion Paper V-48-07, University of Passau, Passau.

Inklaar, R.C., O’Mahony, M. \& Timmer, M.P. (2005) "ICT and Europe's Productivity Performance; Industry-level Growth Account Comparisons with the United States", Review of Income and Wealth, Vo 51 No 4, pp. 505-536.

Kenney, M. (2003) "The Growth and Development of the Internet in the United States", in: B. Kogut (ed.) The Global Internet Economy, The MIT Press, Cambridge, MA, pp.69-108.

Laudon, K. \& Traver, C. (2008) E-Commerce: Business, Technology, Society, 4th Edition, Prentice Hall, New Jersey.

Li, J., Mitra, J. \& Matlay, H. (2004) "E-Commerce and Management of Channel Conflict: Evidence from Small Manufacturing Firms in the UK", International Journal of Technology Management, Vol 28 No 7/8, pp.747-766.

Lockett, N. \& Brown, D.H. (2006) "Aggregation and the Role of Trusted Third Parties in SME eBusiness Engagement: A Regional Policy Issue", International Small Business Journal, Vol 24 No 4, pp. 379-404.

Lucas, A. (1996) "What in the World is Electronic Commerce?", Sales and Marketing Management, June, pp. 24-29.

Martin, L.M. (2005) "Internet adoption and use in small firms: internal processes, organisational culture and the roles of the owner-manager and key staff", New Technology, Work and Employment, Vol 20 No 3, pp. 190-204.

Martin, L. \& Matlay, H. (2001) "Blanket Approaches to Promoting ICT in Small Firms: Some Lessons from the DTI Ladder Adoption Model in the UK", Journal of Internet Research, Vol 11 No 5, pp. 399-410. 
Martin, L. \& Matlay, H. (2003) "Innovative Use of the Internet in Established Small Firms: The Impact of Knowledge Management and Organisational Learning in Accessing New Opportunities", Qualitative Market Research, Vol 6 No 1, pp. 18-26.

Matlay, H. (1998) Organisational Innovation, Knowledge Management and Team Learning in SMEs: A Resource Based Perspective, UCE Business School Research Seminar, June, University of Central England, Birmingham.

Matlay, H. (2003a) "Small Tourism Firms in e-Europe: Definitional, Conceptual and Contextual Considerations", in: R. Thomas (ed.) Small Firms in Tourism: International Perspectives, Pergamon, Oxford, pp. 297-312.

Matlay, H. (2003b) e-Babel: In Search of a Theory of e-Everything, UCE Business School Research Seminar, March, University of Central England, Birmingham.

Matlay, H. (2004) "Training and Human Resource Issues in Small e-Businesses: Towards a Research Agenda", Education and Training, Vol 46 No 8/9, pp. 520-526.

Matlay, H. (2005) Beyond Innovation: Collaboration and Competition amongst Small e-Businesses in Europe, UCE Business School Research Seminar, February, University of Central England, Birmingham.

Matlay, H. (2008) "The Impact of Entrepreneurship Education on Entrepreneurial Outcomes", Journal of Small Business and Enterprise Development, Vol 15 No 2, pp. 382-396.

Matlay, H. \& Addis, M. (2003) "Adoption of ICT and e-Commerce in Small Businesses: an HEIBased Consultancy Perspective", Journal of Small Business and Enterprise Development, Vol 10 No 3, pp. 321-335.

Matlay, H. \& Westhead, P. (2005) "Virtual Teams and the Rise of e-Entrepreneurship in Europe", International Small Business Journal, Vol 12 No 4, pp. 279-300.

Matlay, H. \& Westhead, P. (2007) "Innovation and Collaboration in Virtual Teams of eEntrepreneurs", International Journal of Entrepreneurship and Innovation, Vol 8 No 1, pp. 29-36.

McGuckin, R.H. \& van Ark, B. (2005) Productivity and Participation: An International Comparison, Research Memorandum GD-78, Groningen Growth and Development Centre, Groningen.

Melao, N. (2009) "E-Business, E-Business Processes and E-Business Process Modelling: A Critical Examination and a Framework", International Journal of Services Technology and Management, Forthcoming

Meroño-Cerdan, A., Lopez-Nicolas, C. \& Soto-Acosta, P. (2006) "Analysing Collaboration Technologies Effect on Performance through Intranet Use Orientations", European and Mediterranean Conference on Information Systems, 6-7 July, Costa Blanca, Alicante, Spain.

O'Donnell, A. (2004) "The nature of networking in small firms", Qualitative Market Research: An International Journal, Vol 7 No 3, pp. 206-217.

Papazoglou, M. \& Ribbers, P. (2006) E-Business: Organisational and Technical Foundations, John Wiley and Sons, Chichester.

Pansiri, J. (2005) "Pragmatism: A Methodological Approach to Researching Strategic Alliances in Tourism", Tourism and Hospitality Planning \& Development, Vol 2 No 3, pp. 191-206.

Pansiri, J. (2006) "Doing Tourism Research Using the Pragmatism Paradigm: An Empirical Example", Tourism and Hospitality Planning \& Development, Vol 3 No 3, pp. 223-240. 
Peet, S., Brindley, C. \& Ritchie, B. (2002) "The European Commission and SME Support Mechanisms for e-Business", European Business Review, Vol 14 No 5, pp. 335-341.

Pinker, E.J., Seidmann, A. \& Foster, R.C. (2002) "Strategies for Transitioning 'Old Economy' Firms to e-Business", Communications of the ACM, Vol 45 No 5, pp. 76-83.

Pols, A. (2007) "The Role of Information and Communication Technology in Improving Productivity and Economic Growth in Europe: Empirical Evidence and an Industry View of policy Changes" in: R. Tilly, P.J. Welfens \& M. Heise (eds.) 50 Years of EU Economic Dynamics Integration, Financial Markets and Innovation, Springer, Berlin, pp. 183-202.

Ritchie, J.R. (2005) "Longitudinal research Methods", in: B.W. Ritchie, P. Burns \& C. Palmer (eds.) Tourism Research Methods - Integrating Theory with Practice, CABI Publishing, Wallingford, pp. 131-148.

Sabel, C.F. (1989) "Flexible specialisation and the re-emergence of regional economics", in: P. Hirst \& J. Zeitlin (eds.) Reversing Industrial Decline? Industrial Policy in Britain and Her Competitors, Berg Publishers, Oxford.

Sapir, A. (2006) "Globalization and the Reform of European Social Models", Journal of Common Market Studies, Vol 44 No 2, pp. 369-390.

Schubert P. \& Leimstoll, U. (2008) How SMEs Strive to Achieve Competitive Advantage with ITSupported Business Processes: An Empirical Study, 21st Bled Electronic Commerce Conference, 15-18 June, Bled, Slovenia.

Street, C.T. \& Cameron, A.-F. (2007) "External relationships and the small business: a review of small business alliance and network research", Journal of Small Business Management, Vol 45 No 2, pp. 239-266.

Tilly, R., Welfens, P.J. \& Heise, M. (Eds.) (2007) 50 Years of EU Economic Dynamics Integration, Financial Markets and Innovation, Springer, Berlin.

Timmers, P. (2000) Strategies and Models for Business-to-Business Trading Electronic Commerce, John Wiley and Sons, Chichester.

Van Ark, B. (2006) "Europe’s Productivity Gap: Catching Up or Getting Stuck?", World Economic Performance: Past, Present and Future - Europe, the Americas and Africa Workshop, 27 October, University of Groningen, Groningen.

Volberda, H.W. (1996) "Towards the Flexible Form: How to Remain Vital in Hypercompetitive Environments", Organisation Science, Vol 7 No 4, pp. 359-374.

Waesche, N.M. (2003) Internet Entrepreneurship in Europe, Edward Elgar, Cheltenham.

Walle, A.H. (1997) "Quantitative Versus Qualitative Tourism Research", Annals of Tourism Research, Vol 24 No 3, pp. 524-536.

Welfens, P.J., (2007) "Information and Communication Technology: Dynamics, Integration and Economic Stability", in: R. Tilly, P.J. Welfens \& M. Heise (eds.) 50 Years of EU Economic Dynamics - Integration, Financial Markets and Innovation, Springer, Berlin, pp. 137-182.

Welter, F. \& Kautonen, T. (2005) "Trust, social networks and enterprise development: exploring evidence from East and West Germany", The International Entrepreneurship and Management Journal, Vol 1 No 3, pp. 367-379.

WTO (2007) Tourism Market Trends, 2007 Edition - World Overview, World Tourism Organization, Madrid. 
Wu, D.J. \& Kleindorfer, P.R. (2005) "Competitive Options, Supply Contracting, and Electronic Markets", Management Science, Vol 51 No 3, pp. 452-466.

Zwass, V. (1996) “Electronic Commerce: Structures and Issues”, International Journal of Electronic Commerce, Vol 1 No 1, pp. 3-23. 
